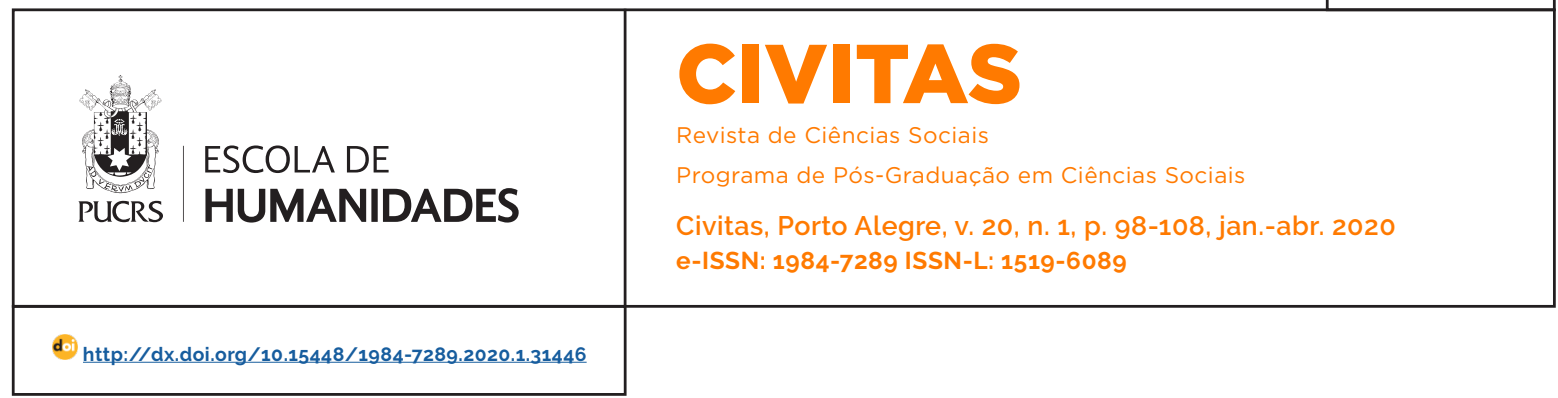

ARTIGOS / ARTICLES

\title{
A dinâmica da participação em conselhos gestores de Itajaí
}

\author{
The dynamics of participation in Itajai management councils \\ La dinámica de la participación en las juntas directivas de Itajai
}

\author{
Águeda Lenita Pereira \\ Wendhausen ${ }^{1}$ \\ orcid.org/0000-0002-0672-5219 \\ aguedalenita@gmail.com
}

\author{
Mayara Ana da Cunha \\ Kersten ${ }^{1}$ \\ orcid.org/0000-0002-6460- \\ 5207 \\ mcunha@univali.br
}

\section{Ana Claudia Delfini Capistrano de Oliveira ${ }^{1}$ orcid.org/0000-0002-7154-9020} anaclaudia.univali@gmail.com

Recebido em: 19 jul. 2018 Aprovado em: 20 jun. 2019 Publicado em: 25 mai. 2020
Resumo: Este artigo apresenta os resultados de uma pesquisa realizada junto aos Conselhos Municipais de Assistência Social e da Criança e do Adolescente de Itajaí, SC. Seu objetivo é analisar as dinâmicas participativas nesses conselhos durante os anos de 2005 e 2006 . Os procedimentos metodológicos foram a coleta e a análise das atas e das pautas discutidas nas reuniões ordinárias e extraordinárias. A análise foi orientada pelos seguintes eixos: o que se informa, o que se discute e o que se decide, com base na observação de quem foram os atores presentes na discussão e quais foram seus pronunciamentos e posicionamentos. Como principais resultados da pesquisa, foi possivel compreender a importância da temática participativa no âmbito dos conselhos ao constatar as limitações e as possibilidades dos processos participativos que poderão, futuramente, melhor qualificar intervenções nesse processo nos municipios pesquisados e em outros que podem se beneficiar dos resultados encontrados.

Palavras-chave: Participação social. Conselhos gestores. Informação.

Resumen: Este artículo presenta los resultados de uma investigación realizada junto a los Consejos Municipales de Asistencia Social y del Niño y del Adolescente de Itajaí/SC. Su objetivo es analizar las dinámicas participativas en estos consejos durante los años 2005 y 2006. Los procedimientos metodológicos fueron la recolección y análisis de las actas y pautas discutidas en las reuniones ordinarias y extraordinarias. El análisis fue orientado por los siguientes ejes: lo que se informa, lo que se discute y lo que se decide, con base en la observación de quienes fueron los actores presentes en la discusión y cuáles fueron sus pronunciamientos y posicionamientos. Como principales resultados de la investigación, fue posible comprender la importancia de la temática participativa en el ámbito de los consejos al constatar limitaciones y posibilidades de los procesos participativos que podrán, en el futuro, mejor calificar intervenciones en este proceso en los municipios investigados y en otros que pueden beneficiarse de los resultados encontrados.

Palabras clave: Participación social. Consejos de Gestión. Información.

Abstract: This article presents the results of a survey carried out by the Municipal Councils for Social Welfare and for the Welfare of Children and Adolescents of Itajai, in the state of Santa Catarina. Its main objective is to analyze the participatory dynamics of counselors during 2005 and 2006. The methodological procedures used were the collection and subsequent analysis of the data contained in the minutes of the meetings, and in the agendas discussed at meetings ordinary and extraordinary. The analysis was guided by the following axes: what is informed, what is discussed, and what is decided, based on the observation of the actors who were present in the discussions, and their statements and positions. As the main results of the survey, it was possible to understand the importance of participatory theme in the context of the councils enabled us to understand the limitations and possibilities of participatory processes that may, in the future. better qualify interventions in this process in the municipalities surveyed and in others, which can benefit from the results of this study.

Keywords: Social participation. Management councils. Information.
Artigo está licenciado sob forma de uma licença Creative Commons Atribuição 4.0 Internacional.

(n)




\section{Introdução}

A Constituição da República Federativa do Brasil é fruto de um intenso cenário de redemocratização e ampliação da participação popular graças aos movimentos sociais reivindicatórios pela redemocratização do Brasil, cujas implicações foram sentidas em diversas áreas da vida econômica, política e social. Disto decorre um dos mais importantes princípios constitucionais: a participação social nos canais institucionais da política com a revalorização do lugar da sociedade civil na gestão pública, condição sine qua non para que os espaços políticos, nos quais se definem as políticas sociais, sejam efetivamente democratizados e devidamente controlados pela sociedade civil. ${ }^{2}$

Os conselhos gestores de políticas públicas são um espaço potencial tanto para a inserção de representantes da sociedade civil no processo deliberativo das políticas públicas quanto para o monitoramento da própria política pública. A participação da sociedade civil nos conselhos é, de fato, imprescindivel para a qualidade e a efetividade da implementação das políticas públicas, o que torna necessário analisar as dinâmicas de participação dos conselheiros nestes espaços para que se possa avançar nas discussões sobre a participação democrática.

Se quisermos problematizar a participação democrática mediante a consolidação da institucionalidade protagonizada pelos conselhos gestores, deve-se ter em mente dois pontos de vista apontados por Tatagiba $(2002,74)$ : o políicosocietal e o político-institucional, sendo esse último privilegiado neste artigo, cujo objetivo é analisar as dinâmicas de participação dos conselheiros mediante a observação participante das pesquisadoras nas reuniões ordinárias e extraordinárias durante os anos de 2005 e 2006 em dois Conselhos Municipais na cidade de Itajai: o de Assistência Social e o da Criança e do Adolescente. Importa pontuar que as diferenças entre os Conselhos referem-se ao tempo sócio-histórico. já que os Conselhos da Criança e do Adolescente surgiram após a estruturação do Estatuto da Criança e do Adolescente em 1990, e os Conselhos de Assistência Social foram implementados após o Sistema Único de Assistência Social (20042005), o que exigiu mais capacidade deliberativa por parte dos conselheiros.

Tais Conselhos foram selecionados em razão de sua maior disseminação nos municipios brasileiros, ao lado dos Conselhos das áreas da Saúde e da Educação, com uma cobertura de 90\% nos municipios brasileiros, além de serem conselhos com grande repasse de verbas do Governo Federal. No campo das políticas setoriais monitoradas pelos conselhos, é fundamental a discussão sobre as dinâmicas de participação dos conselheiros em relação às informações e os debates por eles encaminhados tanto nas proposições quanto na execução das políticas públicas (Gohn 2001).

Em Santa Catarina, segundo o IBGE, ${ }^{3}$ registrase 295 municípios com 287 Conselhos da Criança e do Adolescente e 295 Conselhos de Assistência Social, ambos com forte inserção social. A cidade de Itajai foi selecionada por ser considerada um município polo da microrregião do Vale do Itajai que congrega onze municipios e destaca-se como centro portuário do Estado.

A pesquisa realizada está classificada como exploratória e qualitativa, seus procedimentos metodológicos foram realizados em duas etapas: a primeira foi a observação participante das pesquisadoras nas reuniões ordinárias e extraordinárias durante os anos de 2005 e 2006 , seguida da coleta e posterior análise dos dados contidos nas atas e pautas discutidas nessas reuniões.

\section{Conselhos gestores e participação democrática no Brasil}

Os conselhos gestores são órgãos públicos, pertencentes ao executivo, cujo papel é deliberar e/ou aconselhar na definição e no controle das políticas públicas. Existem em nivel federal, estadual e municipal. São compostos de representantes da

\footnotetext{
Senado Federal. 1988. Constituição da República Federativa do Brasil. Acessado em 1 jul., 2018, https://www2.senado.leg.br/bdsf/ bitstream/handle/id/518231/CF88_Livro_EC91_2016.pdf.

IBGE. s. d. Panorama cidades IBGE. Acessado em 6 jul., 2018, https://cidades.ibge.gov.br/brasil/sc/itajai/panorama.
} 
sociedade civil e do governo, normalmente de forma paritária. As principais funções de cada conselho são: formular estratégias para as politicas públicas; discutir a destinação dos recursos de cada fundo; e alocar e administrar os recursos a fim de garantir mais beneficios à população, em junção com o Governo Federal, Estadual ou Municipal. Nas palavras de Vaz (2011, 167):

Conselhos Gestores são instituições compostas de forma paritária por membros do governo e da sociedade civil para deliberação sobre as bases e condições de políticas públicas específicas que variam desde a temática da saúde, de assistência social, criança e adolescente. até a de patrimônio público e cultural.

Para Teixeira e Carvalho (2000) os conselhos gestores são canais de participação da sociedade civil, formas inovadoras de gestão pública que permitem o exercício de uma cidadania ativa, incorporando as forças vivas de uma comunidade à gestão de seus problemas e à implementação de políticas públicas que possam solucioná-los. Os conselhos são importantes porque são fruto de lutas e de demandas populares, e de pressões da sociedade civil pela democratização do país, cujo caráter interinstitucional demonstra-se na mediação das relações entre sociedade civil e Estado e na qualidade de instrumentos de expressão. representação e participação da população.

Teixeira (2001) define a participação como uma relação em que atores (coletivos e individuais) com os recursos disponiveis nos espaços públicos, fazem valer seus interesses, aspirações e valores, construindo suas identidades como cidadãos ativos, capazes de interferir, interagir e influenciar na construção de um senso de ordem pública regida pelos critérios de equidade e justiça.

Observando a história da participação nos paises latino-americanos, Gohn (2001) constata que no universo da política, a participação dos individuos na sociedade civil ou politica tornouse parte do vocábulo e da agenda das nações ocidentais, a partir dos anos 1960 do século 20. São distintas as formas de se compreender tal participação, algumas são consideradas clássicas e deram origem a interpretações, significados e estratégias distintas, dentre elas estão: a liberal (todos os membros da sociedade são iguais e a participação seria o instrumento para busca de satisfação dessas necessidades); a autoritária (é aquela orientada para a integração e o controle social da sociedade e da política); a revolucionária (estruturada em coletivos organizados para lutar contra as relações de dominação e pela divisão do poder político) e a democrática (criação de uma cultura de dividir as responsabilidades na construção coletiva de um processo).

Ao final da década de 1980, com o fim dos regimes políticos militares vigentes em grande número de paises latino-americanos, a participação da sociedade civil ganhou força nos debates políticos, sobretudo com a criação de mecanismos participatórios. Tais mecanismos vieram em decorrência de três fatores: em primeiro lugar, a desilusão com as instituições políticas verificada em várias democracias liberais ocidentais nos anos 1960; em segundo lugar, o crescimento dos novos movimentos sociais a partir dos anos 1970 e; em terceiro lugar, a crise econômica mundial verificada ao final do século 20. Os movimentos sociais deveriam exercer pressão e servir como fiscalizadores sobre uma burocracia resistente às mudanças (Cortês 1996).

Dentro desta perspectiva participatória, a sociedade civil se amplia para entrelaçar-se com a sociedade política, colaborando para o novo caráter contraditório e fragmentado que o Estado passa a ter na década de 1990. Desenvolve-se o novo espaço público não estatal, onde irão situar-se os conselhos, os fóruns e as articulações entre a sociedade civil e os representantes do poder público no tocante ao atendimento das demandas sociais (Gohn 2001).

Como revelam as pesquisas de Almeida e Tabagiba (2012), ${ }^{4}$ no campo das politicas setoriais monitoradas pelos conselhos, a discussão sobre a qualidade da democracia deve passar pelas análises das dinâmicas de participação dos 
conselheiros, seu grau de autonomia e o caráter representativo das organizações da sociedade civil na proposição e execução das políticas públicas. Os estudos sobre conselhos gestores na área das Ciências Sociais e da Ciência Política no Brasil têm mostrado que os governos mais sólidos, em termos de governança democrática, foram aqueles que tiveram apoio de uma sociedade civil ativa conjugada com o fortalecimento de instituições e de ações participativas como as associações da sociedade civil, as experiências de orçamentos participativos, a realização de conferências propositivas e deliberativas sobre diversos segmentos das políticas públicas (Borba e Seibel 1998; Dagnino 2002; Avritzer e Navarro 2003).

As dinâmicas participativas são aqui compreendidas como o exercício do direito constitucional da participação e da representação das entidades da sociedade civil que possuem assento nos conselhos e são, portanto, agentes principais na tomada de decisão e na implementação de políticas públicas. Como lembram Vieira e Calvo (2011, 2316):

A participação social na área da política compreende toda e qualquer forma, individual ou coletiva, de envolvimento do cidadão em atividades políticas, quais sejam: eleição de representantes; a militância em partido político; o exercício da função pública; o engajamento em associações de natureza política ou social; a manifestação pública de opinião; a ação organizada em grupos de pressão; a fiscalização dos serviços públicos; a realização de denúncias; o trabalho de conscientização política, entre outras [...] Tal exercicio da democracia participativa constitui a participação popular. conceituada como um processo político concreto que se produz na dinâmica da sociedade, mediante a intervenção cotidiana e consciente de cidadãos, individualmente considerados ou organizados em grupos e/ou associações, visando à elaboração e implementação ou à fiscalização das atividades do poder público.

Se por um lado já existe uma forte institucionalização dos conselhos na cultura política brasileira, atestada pela sua disseminação nos municipios chegando a quase $100 \%$ de municípios com conselhos nas áreas da Saúde, da Educação e da Assistência Social, por outro, esta "arquitetura de participação", na fala de Almeida e Tatagiba (2012, 71-72), não garante nem assegura a qualidade da democracia uma vez que:

\begin{abstract}
[...] as disputas travadas no interior dos conselhos parecem ter dificuldades de extrapolar suas fronteiras e repercutir no ambiente políticosocietal e politicoinstitucional de forma mais ampla, o que limita seu poder na conformação das políticas setoriais, com impactos sensiveis sobre sua capacidade de democratizar as politicas públicas. Para reverter esse quadro, argumentamos também que é necessário rever as rotinas dos conselhos. [...]. Estamos entendendo política como a ação que traz para a arena pública demandas por justiça que interpelam consensos e regras instituídas. Uma ação, portanto, que legitima e arma conflitos na sociedade visando, mediante negociações públicas, a redefinição dos termos sobre os quais se organizam o Estado e a sociedade. É preciso restituir o lugar desse tipo de ação na agenda dos conselhos para que eles possam funcionar como instâncias de democratização da gestão pública, e não restritamente como espaço de disputa entre interesses corporativos das comunidades de política, o que hoje parece ser a regra.
\end{abstract}

No caso especifico da participação politica no interior dos conselhos, as dinâmicas participativas são mais complexas em razão das relações de poder existentes tanto no que diz respeito às dimensões estruturais quanto à "interação concreta entre elas, já que os constrangimentos socioeconômicos, simbólicos e políticos podem funcionar como poderoso obstáculo à participação" (Vieira e Calvo 2011, 2316).

\section{As dinâmicas de participação}

A análise dos conteúdos das práticas se deu a partir das atas de reuniões efetuadas durante os anos de 2005 e 2006, em um total de 54 atas nos dois conselhos, 32 do Conselho da Criança e do Adolescente e 20 do Conselho da Assistência Social. Para a análise foi selecionada uma amostra de 16 atas exclusivamente das reuniões ordinárias do Conselho da Criança e do Adolescente e 10 do Conselho da Assistência Social

Para a análise dos dados utilizou-se a análise de conteúdo, na forma da análise temática proposta por Minayo (1999) que consiste na busca dos núcleos de sentido nas falas dos sujeitos da pesquisa. Tais núcleos foram destacados nas falas dos participantes dos conselhos, registradas em ata, cuja presença ou frequência poderiam 
significar algo para a construção do conhecimento acerca do tema da pesquisa. Os núcleos de sentido que compõem os registros das atas nas reuniões dos conselhos foram agrupados nos seguintes eixos: o que era informado, discutido e decidido com identificação do setor de representação ("governamental", "não governamental", "visitante" e "indeterminado" quando não havia identificação dos atores), dos temas abordados, e de que forma se dão os pronunciamentos e posicionamentos dos conselheiros. ${ }^{5}$

O Conselho Municipal de Assistência Social de Itajai foi implantado pela Lei n. 3.075 de 10 de maio de 1996 que regula os recursos provenientes do Fundo Municipal de Assistência Social. É o órgão que delibera, fiscaliza e destina a implementação desses recursos. ${ }^{6}$ É composto por 18 conselheiros titulares e respectivos suplentes, sendo nove da representação governamental e nove das organizações não governamentais. Esse Conselho apresenta maior detalhamento das discussões, o que permite uma visualização mais clara das dinâmicas participativas. Quando se inicia a discussão de um assunto todos participam, até mesmo os visitantes, vários deles acadêmicos da universidade local ou pessoas que prestam atendimento voluntário aos adolescentes.

Uma situação comum nesse conselho é a falta de quórum nas reuniões, principalmente dos conselheiros governamentais. Também observamos que os temas discutidos nas reuniões são pouco explicitados nas atas, que no geral são curtas, contendo de uma a duas páginas e não expressam o verdadeiro andamento da reunião. A pauta é elaborada pela mesa diretora e encaminhada aos conselheiros por correio eletrônico. Quando há quórum são definidos temas como repasse de verbas e/ou fiscalização de entidades; quando não há participantes suficientes há apenas repasse de informações relacionadas à burocracia.

O Conselho Municipal da Criança e do
Adolescente de Itajaí foi instituido pela Lei $\mathrm{n}$. 2.891 de 20 de dezembro de 1993. Sendo um órgão de deliberação, é consultivo, normativo e controlador da politica de atendimento e das ações em todos os níveis, assegurada a participação popular e observada a composição paritária por meio de organizações representativas, vinculado à Secretaria da Criança e do Adolescente.? Esse conselho não apresenta problemas de quórum, diferente do anterior, a pauta é elaborada pela presidente e pela secretária do Conselho, porém podem ser incluídos assuntos a pedido de conselheiros ou entidades, o que devem ser encaminhados por correio eletrônico, no dia anterior da reunião. O conselho é, também, o órgão captador e aplicador de recursos do Fundo Municipal de Atendimento à Criança e Adolescente conforme regulamentado pela Lei n. 2.891/93.

Nas reuniões, participavam regularmente visitantes que apresentavam projetos ou eram chamados para explicar determinados assuntos. A formulação das atas não é adequada, possui problemas na redação gramatical que compromete a compreensão e a composição do texto. Outro problema identificado foi a ausência de padronização na identificação dos atores da politica: nomeiam nas atas, frequentemente, os conselheiros por apelidos, o que dificultou sua identificação em termos de representação.

Outro detalhe examinado foi a formação da sala de reuniões nos dois conselhos. $O$ da Criança e Adolescente apresentava um formato bem mais circular, onde era possivel os participantes se verem frente a frente, enquanto as reuniões da Assistência Social eram realizadas em local em que a formalidade (cadeiras fixas, distância entre as pessoas) não permitia uma maior flexibilidade e aproximação das pessoas. Estes dados podem ser reveladores da forma como se dá a dinâmica em cada um dos conselhos estudados, pois a arquitetura de certa forma denuncia as práticas

\footnotetext{
5 Quanto aos procedimentos éticos, cada conselho foi informado sobre os objetivos da pesquisa com garantia de sigilo quanto à identidade dos conselheiros e autorização para execução do projeto obtida junto ao Comitê de Ética com seus respectivos Termos de Consentimento Livre e Esclarecido.

6 Conselho Municipal de Assistência Social. 1996. Lei n. 3.075 de 10 de maio de 1996. Acessado em 6 jul., 2018, https://cm-itajai.jusbrasil. com.br/legislacao/767423/lei-3075-96/.

7 Conselho Municipal dos Direitos da Criança e do Adolescente. 1993. Lei n. 2.891 de 20 de dezembro de 1993. Acessado em 6 jul., 2018 https://cm-itajai.jusbrasil.com.br/legislacao/769754/lei-2891-93/.
} 
correspondentes, mais ou menos democráticas, mais ou menos ritualisticas e formais.

Em relação aos registros categorizados: no Conselho da Criança e do Adolescente, foram identificadas ao todo 321 registros de falas. Dessas, $41,74 \%$ são falas procedentes das entidades governamentais e 38,31\% das não governamentais; os visitantes representaram 10,28\% e as falas que denominamos indeterminadas corresponderam a 9,65\%. A partir das observações participantes e das atas, constatamos que o Conselho da Criança e do Adolescente apresenta uma riqueza maior de dados em relação ao Conselho da Assistência Social, seja em número de reuniões, que é bem maior, seja pelo quórum mais constante, seja pela intensidade da discussão nas reuniões. A prova disso é que no período analisado, o Conselho da Criança e do Adolescente realizou oito reuniões extraordinárias.

No Conselho da Assistência foram 91 registros, sendo $35,16 \%$ dos representantes governamentais e 34,06\% dos não governamentais; os visitantes perfizeram $12,08 \%$ e os registros indeterminados somaram 18,68\%. As atas do Conselho de Assistência Social acabaram por repetir o que foi encontrado por Perissinotto (2004) em pesquisa no Conselho Municipal de Assistência Social no estado do Paraná: a ata como um registro formale filtrado das decisões e eventuais discussões que ocorreram no interior da instituição, cujo ambiente descrito é marcado por uma profunda "harmonia", o que não necessariamente é o que acontece.

Observamos que há um equilibrio na distribuição das falas dos segmentos governamental e não governamental o que consideramos um fato positivo, pois a representatividade tem a ver com a possibilidade de que todos os segmentos possam vocalizar suas demandas. Entretanto, nem sempre há uma distribuição equitativa dos vários representantes e a fala pode ser apenas algo formal, o que não reflete as relações de poder que as permeiam como veremos adiante.

Nos dois conselhos observamos o grande número de registros correspondente a participação dos "visitantes" (10\% a 12\%). Concordamos com Fuks (2004a, 2004b) que a existência de "atores externos" demonstra a permeabilidade do conselho em que participação não é apenas aparente, nem apenas assume a forma de uma vitrine, ela é substantiva. Em termos do tipo de registros, ativemo-nos em verificar três tipos de discursos em relação à forma do que se fala nos Conselhos: o que se informa, o que se discute e o que se decide. No Conselho da Criança e do Adolescente identificamos 349 registros: 48,42\% se referem a informações; 34,38\%, a registros de discussões e 17,19\% são relativas a decisões. No Conselho da Assistência Social tivemos 126 registros: 49,2\% de informações; $20,63 \%$ de registros de discussão e 30,15\% de decisões. 0 gráfico 1, ilustra melhor essas constatações.

Gráfico 1 - Distribuição de registros das unidades de análise "o que se informa", "o que se discute" e "o que se decide" nos Conselho da Assistência Social e Conselho da Criança e do Adolescente - Itajaí.

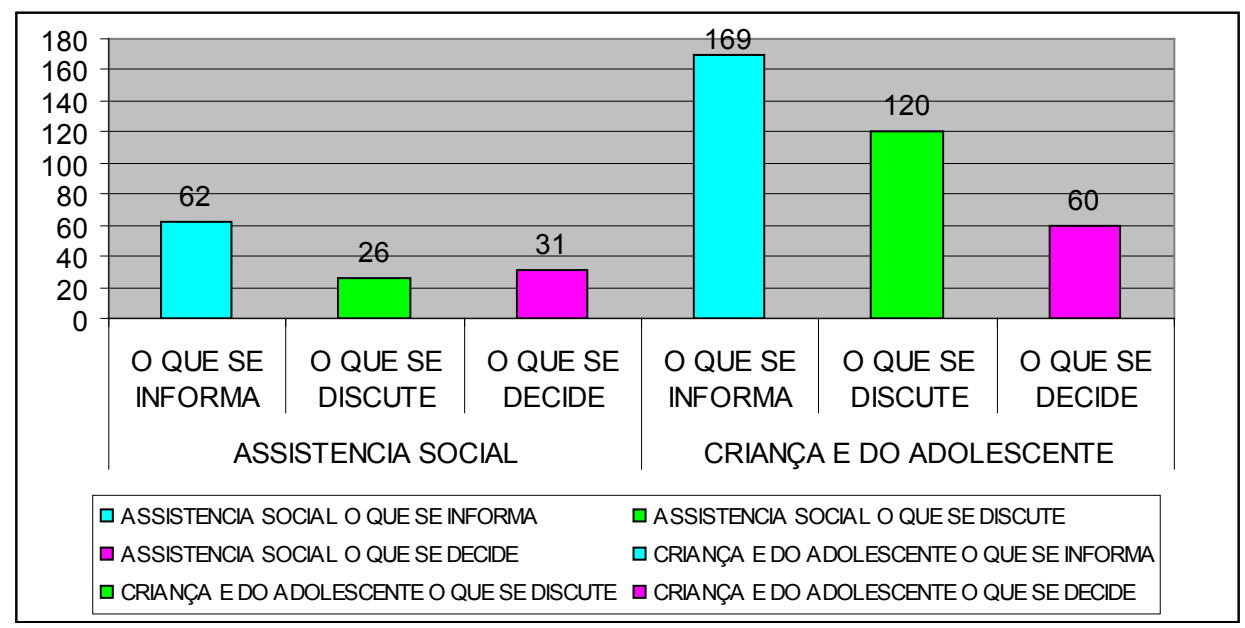

Fonte: Elaborado pelas autoras com base nas Atas do Conselho Municipal da Criança e do Adolescente e Conselho Municipal da Assistência Social de Itajai/SC, gestão 2005-2006. 
O Conselho da Criança e do Adolescente realiza mais reuniões do que o da Assistência Social. Chama atenção que enquanto no primeiro há um equilibrio entre informação e discussão e um número bem menor de decisões; no segundo a realidade é bem diferente, ou seja, há mais informação, bem pouca discussão e muitas decisões. Isso parece denotar que esse último conselho pouco discute antes de tomar suas decisões; que elas já vêm pré-formatadas. No Conselho da Criança e do Adolescente através da unidade de análise a respeito do que se informa, constatou-se a predominância das informações em relação aos esclarecimentos, convites e solicitações. No Conselho da Assistência Social as informações também se sobressaem em relação aos esclarecimentos, convites e solicitações. No Conselho da Criança e do Adolescente quem mais informa são os conselheiros não governamentais, ao contrário do Conselho de Assistência Social, que são os governamentais.

Consideramos que as informações são necessárias para o andamento do conselho, para o processo decisório. Nas observações e nas atas pudemos constatar que no Conselho da Assistência Social, muitas vezes, a presidente coloca um assunto, a vice-presidente se manifesta e, após, há um silêncio na plenária, não havendo mais nenhuma manifestação, o que sugere uma concordância com o que está sendo colocado. Por exemplo, na ata n. 4 encontramos uma fala da presidente e da vice, ao que não há nenhuma manifestação de outros conselheiros.

\begin{abstract}
[...] a presidente relatou sua preocupação em relação à habilitação ou não do municipio de Itajai ao Suas uma vez que neste exato momento o gestor municipal da Assistência Social colocou o cargo a disposição e não há até o momento definição em relação a este ato. Relatou ainda que o prazo para entrega proposta municipal de habilitação é dia nove de agosto e até o momento a secretaria não iniciou a discussão em relação a este assunto A vice-presidente verbalizou sua indignação em relação a este assunto, uma vez que no final de 2004, na fase de transição foi solicitado reunião com o prefeito para debater unicamente este assunto, mas não houve interesse por parte do mesmo. (Conselho Municipal de Assistência Social, ata n. 4, julho, 2005)
\end{abstract}

Após esse assunto não observamos nenhuma outra manifestação, pelo menos em ata, por parte dos conselheiros, especialmente os não governamentais, pois a questão da habilitação do município é assunto que deve ser discutido, como foi ressaltado pela vice-presidente, que era representante do segmento não governamental.

Em relação à unidade de análise sobre o que se discute, observamos que na discussão, a depender de sua qualidade, há uma grande possibilidade de que a participação possa se tornar mais concreta e qualificada. Assim, expomos o gráfico 2, que expressa a diferenciação das discussões nos dois conselhos.

Gráfico 2 - Frequência dos registros referentes "ao que se discute" - Conselhos da Criança e do Adolescente e Assistência Social, Itajai/SC.

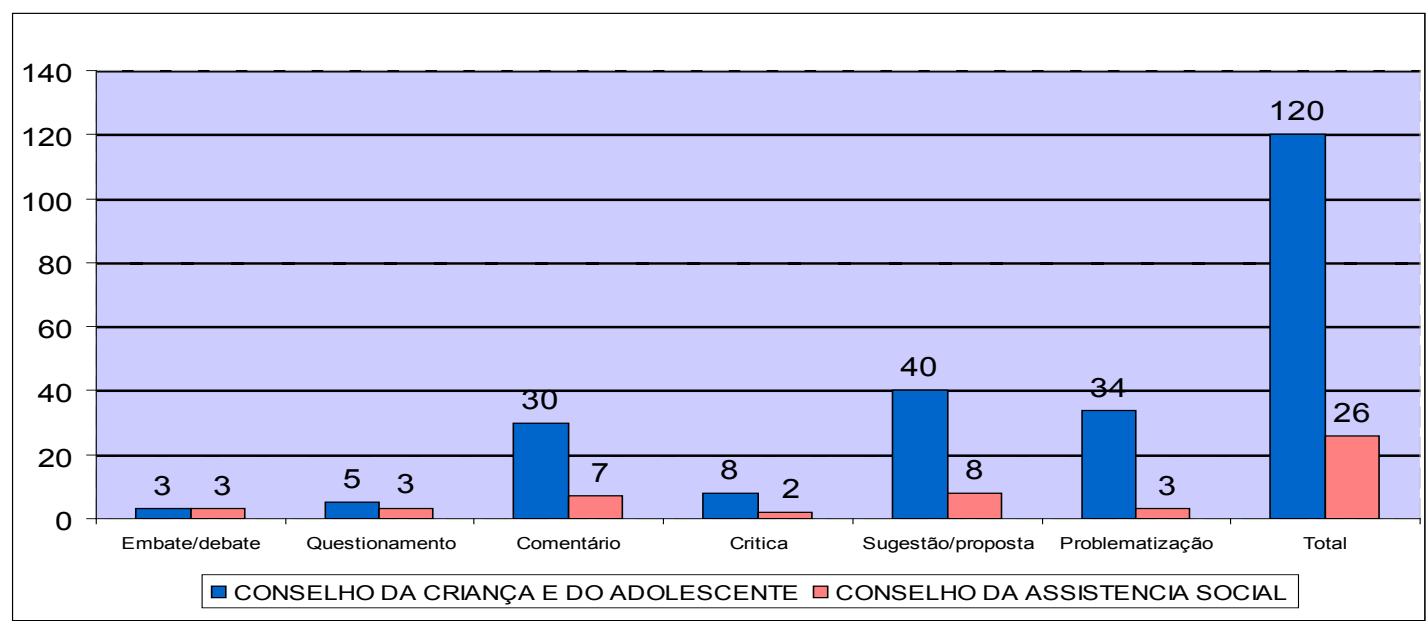

Fonte: Elaborado pelas autoras com base nas Atas do Conselho Municipal da Criança e do Adolescente e Conselho de Assistência Social de Itajai/SC, gestão 2005-2006. 
Através da comparação, observa-se que se discute mais no Conselho da Criança e do Adolescente do que no Conselho da Assistência Social: são 120 registros do primeiro contra 26 do segundo. Ao classificarmos os elementos da discussão encontramos que se sobressaem: no Conselho da Criança e Adolescente os registros de Sugestões (40), Problematizações (34) e Comentários (30); no da Assistência Social, Comentários (7) e Sugestões (8).

O que classificamos como Questionamentos, Embate/debates e Criticas, praticamente inexistem em ambos os conselhos: no da Criança e Adolescente são 5 questionamentos, 3 embate/ debates e 8 criticas e no de Assistência Social são 5 registros ao todo. Mesmo ressaltando que no Conselho da Criança e Adolescente se "conversa mais", em ambos, esses últimos elementos que estão rarefeitos são os que dariam consistência a um espaço que se pretende democrático.

Os questionamentos, embate/debates e criticas provocam um maior "debate de ideias" do que as sugestões e comentários que nos dois conselhos ultrapassam os 50\% dos registros de discussão. As unidades de análise de maior percentual são as que menos provocam "confrontação de ideias" o que levaria a uma maior e mais profunda discussão da pauta antes das decisões.

Segundo Tonella (2004), o debate de ideias e a confrontação de propostas contribuem para o aprofundamento das reflexões e para a melhoria do convívio democrático. Mas o que mais chama atenção é que no Conselho de Assistência Social, especialmente nos momentos de decisão, em que se esperaria uma discussão dos presentes, essas são tomadas imediatamente.

A esse respeito, Perissinotto (2004) em estudo realizado no Conselho Municipal de Assistência Social do Paraná, também constata tanto na análise das atas, como na observação direta, a quase absoluta ausência de debates dentro da instituição, o que faz deste fórum uma instância estritamente decisória e não uma arena pública de debate em torno do que deve ser uma política de assistência social.

Constatamos que pouco se debateu dentro dos conselhos estudados, porém, esse dado se repete em outros conselhos pelo país mostrando que a falta de discussão dentro do conselho não é um problema local. Em pesquisa realizada por Souza (2005) no Conselho de Direito da Criança e do Adolescente de Curitiba, de um total de 653 registros, $12 \%$ corresponde à unidade de análise de debates, ou seja, pouco se discute.

Ao avaliarmos quem se pronuncia, observamos nos registros de discussão que nos dois conselhos os representantes não governamentais discutem mais do que os representantes governamentais. Chama atenção que no Conselho da Assistência Social, mesmo o presidente sendo do segmento governamental, existiam participantes que contestavam frequentemente suas falas, especialmente a vice-presidente, que pertencia ao segmento não governamental. Entretanto, a discussão era bem polarizada, porém restrita praticamente à mesa diretora.

No Conselho da Criança e Adolescente temos que considerar que a secretária e a presidente na gestão de 2006 eram representantes não governamentais e grande parte dos inícios de discussão foram propostos por elas. De qualquer forma, as manifestações de questionamento advêm mais do segmento não governamental e de visitantes, como ilustramos no trecho a seguir.

A visitante fez uso da palavra e informou que sente dificuldades em relação ao acolhimento de adolescentes, principalmente em um abrigo municipal por falta de uma equipe técnica que realize um trabalho especifico. Dois conselheiros não-governamentais questionaram qual é o perfil do profissional que está atuando no abrigo e como está a coordenação. Outra visitante colocou que a demanda para a equipe técnica da secretaria é muito grande e estariam articulando um profissional para estar trabalhando diretamente e exclusivamente no abrigo municipal. Informou que os educadores sociais que trabalham no abrigo, em relação à escolaridade são de nivel médio e recebem capacitação da equipe técnica da Secretaria da Criança e do Adolescente. O Secretário da Criança e Adolescente (visitante) informou que pela legislação os educadores sociais podem ser de ensino fundamental e que a Secretaria optou por ensino médio. Conselheiro não governamental questionou se existem propostas de contratação de equipe e orçamento para implementar o atendimento. (ITAJAI, Comdica. 2006. Conselho Municipal da Criança e do Adolescente. In Atas do Comdica, n. 13. Itajaí, julho de 2006) 
O tom da reunião no Conselho da Criança e do Adolescente é de debate. Há mais diálogo antes da tomada de decisões, por isso, se decide menos, mas provavelmente com mais qualidade democrática.

Observamos, também, que a mesa diretora possui grande importância dentro dos conselhos, pois é ela quem designa quais os temas que serão discutidos. Também em pesquisa realizada por Souza (2005) no Conselho da Criança e do Adolescente de Curitiba, nas poucas vezes em que houve diálogo na arena, constatou-se uma centralização de fala em grupos ligados ao Estado e/ou à direção do Conselho. A forte presença que vem se registrando pelo grupo de apoio técnico pode indicar um baixo nivel de politização na arena.

Isso também, segundo Gohn (2001), pode estar ligado ao fato de que muitos representantes do governo ou do sistema privado apenas toleram os conselhos, porque estão previstos institucionalmente. Na prática são refratários a essa forma de controle social e agem buscando reduzir o seu papel fiscalizador ou deliberativo a meros rituais de legitimação de políticas e decisões supostamente democráticas.

Outra questão problemática para a participação nos conselhos se relaciona às dessimetrias entre seus participantes. Borba (2004) e Wendhausen (1999, 2002) destacam as "desigualdades do poder" entre os vários atores participantes dos conselhos, em geral, derivadas da dicotomia "saber técnico" versus "saber popular".

Tratando especificamente do processo de discussão dos temas levados aos conselhos, destacamos aqui a desigualdade relativa aos técnicos, especialmente, de médicos ou de advogados, pois sua figura têm uma representação simbólica de autoridade e de poder que pode silenciar com facilidade possiveis questionamentos ou problematizações que poderiam ser feitas pelos participantes. Durante as observações identificamos essa situação no Conselho da Criança e do Adolescente, que possuía em sua composição um conselheiro que além de médico, era o Secretário da Criança e do Adolescente. Após seus comentários, poucos questionavam e até mesmo demonstravam manifestações elogiosas por suas palavras. Outra questão a ser levantada é que, tanto no Conselho da Criança e do Adolescente quanto no Conselho da Assistência Social, as decisões são apenas registradas em ata, mas não são oficializadas em forma de resolução, moções ou recomendações.

\section{Considerações finais}

Há uma maior disposição/oportunidade dos conselheiros do Conselho da Criança e do Adolescente para dialogar, o que se reforça no formato arquitetônico das reuniões, de atas mais bem elaboradas, de maior número de reuniões e de uma participação mais efetiva nas mesmas. Já no Conselho da Assistência Social verificamos uma constante falta de quórum, pouca discussão, expressos em atas muito sintéticas, que não retratam a verdadeira dinâmica das reuniões.

Ambos os conselhos informam mais do que discutem, porém no Conselho da Criança e do Adolescente as discussões são muito mais frequentes do que no Conselho da Assistência. No entanto, ao aprofundarmos a qualidade das discussões, observou-se que pouco se "debate" ou "critica". Na maioria das vezes as discussões se resumem a questionamentos e comentários que perfazem $50 \%$ dos registros de discussão. Ou seja, as unidades de análise de menor percentual são as que menos provocam "confrontação de ideias", o que levaria a uma maior e mais profunda discussão da pauta antes das decisões.

Ressalta-se a presença de um maior número de registros de falas dos representantes governamentais no Conselho da Criança e do Adolescente. No Conselho da Assistência Social o maior número de falas advém dos representantes não governamentais, porém quase se equiparando aos governamentais. Nos dois conselhos a participação de visitantes é frequente, tendo um peso importante na formulação da agenda dos conselhos, o que demonstra a permeabilidade desses fóruns à sociedade civil.

As decisões nos dois conselhos, em sua totalidade, apresentam apenas registros nas atas, fato que causa preocupação, pois as decisões tomadas deveriam ser no formato de resolução 
e publicadas em veículo oficial de informação. Verifica-se que debater sobre a dinâmica da participação dos conselhos revela muito mais do que disposição das cadeiras ou a quantidade de conselheiros para compor o quórum, retrata que essa dinâmica interna afeta diretamente a qualidade democrática exercida por esses conselhos.

Este debate é importante uma vez que a dinâmica interna de participação é fundamental para a qualidade democrática, para o aperfeiçoamento dos processos participativos no cotidiano dos conselhos, a fim de refletir as necessidades e as potencialidades das discussões políticas ali entabuladas.

Não se pode esquecer que o ponto de partida da criação dos conselhos, em nossa recente história democrática, teve como norte a participação coletiva nas decisões sociais e politicas, razão pela qual ela deve ser potencializada nos espaços dos conselhos. Afinal, os atores da sociedade civil não são portadores necessariamente de uma racionalidade imparcial como se encarnassem em si o bem comum ou o interesse público, mas são portadores de concepções situadas e parciais sobre o que deve ser o bem comum, sendo que a maior parte do tempo essas concepções são conflitantes e, até mesmo, antagônicas entre si.

Apesar dos limites, os conselhos podem contribuir na democratização tanto do Estado, impondo mais responsabilidade pública aos governos, quanto da sociedade, provocando a emergência de novos sujeitos políticos e identidades coletivas e dando voz a setores tradicionalmente excluídos de representação direta no sistema político.

Neste sentido, a consolidação dos conselhos revela-se como processo educativo, que deve se consolidar com o diálogo. Em uma sociedade como a brasileira, carregada de vícios colonialistas, faz-se importante seu exercício cotidiano, pois ainda não costumamos lidar com espaços públicos como algo conflituoso em que se pode e deve exercer, sim, o poder, porém de forma transitiva, ou seja, considerando o outro como um sujeito que tem algo a dizer. Enquanto os representantes que não são do governo forem tratados com pouco ou nenhum peso, continuaremos a viver em uma democracia só de aparência.

\section{Referências}

Almeida, Carla e Luciana Tatagiba. 2012. Conselhos gestores sob o crivo da política: balanços e perspectivas. Serviço Social e Sociedade, n 109: 68-92. http:// $\mathrm{dx}$.doi.org/10.1590/S0101-66282012000100005.

Avritzer, Leonardo e Zander Navarro. 2003. A inovação democrática no Brasil. São Paulo: Cortez.

Borba, Julian. 2004. O significado político dos conselhos gestores de políticas públicas. In II Encontro de Pesquisa em Saúde: o SUS e a atenção à saúde da familia, 33-42, 1 Itajai: Editora da Univali. https://doi. org/10.11606/t.6.2013.tde-31102013-152144.

Borba, Julian e Erni Seibel. 1998. Participação politica e democratização do Estado. Anais do Congresso de Economia Política. Lisboa.

Cortês, Soraia Vargas. 1996. As origens da ideia de participação na área da saúde. Saúde em Debate (51): 30-37.

Dagnino, Evelina. 2002. Sociedade civil e espaços públicos no Brasil. São Paulo: Paz e Terra.

Fuks, Mário. 2004a. Democracia e participação no conselho municipal de saúde de Curitiba (1999-2001). In Democracia e participação: os conselhos gestores do Paraná, organizado por Mário Fuks, Renato Perissonotto e Nelson Rosário Souza. Curitiba: Ed. UFPR. https://doi. org/10.11606/t.6.2013.tde-31102013-152144..

Fuks, Mário. 2004b. Empoderamento e participação da comunidade em políticas sociais. Saúde e Sociedade 13, n 2: 20-31. https://doi.org/10.1590/S010412902004000200003 .

Gohn, Maria da Gloria. 2001. Conselhos gestores e participação sociopolitica. São Paulo: Cortez.

Minayo, Maria Cecilia de Souza. 1999. O desafio do conhecimento pesquisa qualitativa em saúde. São Paulo: Rio de Janeiro: Ed. Hucitec/Abrasco.

Souza, Nelson Rosário. 2005. Cenários e atores: a arena pública do Conselho de Direitos da Criança e do Adolescente de Curitiba (1997-2001). In Democracia e participação: os conselhos gestores do Paraná, organizado por Mário Fuks, Renato Perissinotto e Nelson Rosário Souza, 75-102. Curitiba: Ed. UFPR. https://doi. org/10.5380/nep.v2i3.47417.

Tatagiba, Luciana. 2002. Os conselhos gestores e a democratização das politicas públicas no Brasil. In Sociedade civil e espaços públicos no Brasil, organizado por Evelina Dagnino, 47-105. São Paulo: Paz e Terra

Teixeira, Elenaldo Celso. 2001. O local e o global: limites e desafios da participação cidadã. São Paulo: Cortez.

Teixeira, Ana Claudia e Maria do Carmo Albuquerque A. Carvalho. 2000. Conselhos gestores de politicas públicas. São Paulo: Instituto Pólis. 


\section{8}

Tonella, Celene. 2004. Ampliação da participação democrática: Conselhos gestores de políticas públicas em Maringá. Revista Paranaense de Desenvolvimento, (106): 137-156.

Vaz, Alexander Cambraia N. 2011. Participação politica, efeitos e resultados em políticas públicas: notas critico-analíticas. Opinião Pública 17, n 1: 163-205. http:// dx.doi.org/10.1590/S0104-62762011000100006.

Vieira, Mauro e Maria Cristina Marino Calvo. 2011. Avaliação das condições de atuação de conselhos municipais de saúde no estado de Santa Catarina. Cadernos de Saúde Pública 27, n 12: 2315-2326. https://doi. org/10.1590/S0102-311X2011001200004.

Wendhausen, Águeda. 1999. Micropoderes no cotidiano de um conselho de saúde. Tese em Ciências da Saúde, Ufsc, Florianópolis.

Wendhausen, Águeda. 2002. O duplo sentido do controle social: (des) caminhos da participação em saúde. Itajai: Univali.

\section{Águeda Lenita Pereira Wendhausen}

Doutora em Enfermagem pela Universidade Federal de Santa Catarina (Ufsc, Florianópolis, SC, Brasil). Docente da Graduação em Enfermagem e do Programa de Mestrado em Saúde e Gestão do Trabalho da Universidade do Vale do Itajai (Univali, Itajaí, SC, Brasil).

\section{Mayara Ana da Cunha Kersten}

Doutoranda do Programa de Pós-Graduação em Educação da Universidade do Vale do Itajai (Univali, Itajaí, SC, Brasil).

\section{Ana Claudia Delfini Capistrano de Oliveira}

Doutora em Sociologia pela Universidade Federal de Santa Catarina (Ufsc, Florianópolis, SC, Brasil). Professora titular da Universidade do Vale de Itajai (Univali, Itajaí, SC, Brasil) atuando nos cursos de Direito, Relações Internacionais, no Programa de Mestrado Profissional em Gestão de Políticas Públicas/PMGPP e no Programa de Pós-graduação em Educação (Mestrado e Doutorado). 